\title{
Host-use pattern of the shrimp Periclimenes paivai on the scyphozoan jellyfish Lychnorhiza lucerna: probing for territoriality and inferring its mating system
}

\author{
J. Antonio Baeza ${ }^{1,2,3^{*}}$, Samara de Paiva Barros-Alves ${ }^{4,5}$, Rudá Amorim Lucena ${ }^{6}$, Silvio Felipe Barbosa Lima ${ }^{7,8}$ \\ and Douglas Fernandes Rodrigues Alves ${ }^{4,5}$
}

\begin{abstract}
In symbiotic crustaceans, host-use patterns vary broadly. Some species inhabit host individuals solitarily, other species live in heterosexual pairs, and even other species live in aggregations. This disparity in host-use patterns coupled with considerable differences in host ecology provide opportunities to explore how environmental conditions affect animal behavior. In this study, we explored whether or not symbiotic crustaceans inhabiting relatively large and structurally complex host species live in aggregations. We expected Periclimenes paivai, a small caridean shrimp that lives among the tentacles of the large and morphologically complex scyphozoan jellyfish Lychnorhiza lucerna, to live in groups given that the host traits above constraint host-monopolization behaviors by symbiotic crustaceans. We described the population distribution of P. paivai during a bloom of L. lucerna near the mouth of the Paraíba River estuary in Paraíba, Brazil. The population distribution of P. paivai did not differ statistically from a random Poisson distribution. Male shrimps were most often found dwelling on the surface of L. lucerna individuals as small groups (2-4 individuals), in agreement with expectations. Periclimenes paivai is a sexually dimorphic species with males attaining smaller average body sizes than females and exhibiting no elaborated weaponry (claws). Females, but not males, experience positive allometry in cheliped size and were found living solitarily in small but not large host individuals. The above suggest that females might be territorial or that they might be competing for resources (i.e., food) likely expected to impact their reproductive output. Our results agree, but only partially, with the idea that large and morphologically complex host species should harbor non-territorial gregarious symbiotic crustaceans. Symbiotic crustaceans represent excellent models to improve our understanding about the conditions driving the social behavior of marine organisms.
\end{abstract}

Keywords: Caridea, Spacing system, Palaemonidae, Symbiosis

\section{Introduction}

Members belonging to the infraorder Decapoda, a specious clade of crustaceans [1, 2], develop symbiotic associations (symbiosis here defined sensu [3] as dissimilar organisms living together) with a wide variety of invertebrate and vertebrate hosts, including poriferans,

\footnotetext{
*Correspondence: jbaezam@clemson.edu; baeza.antonio@gmail.com 1 Department of Biological Sciences, Clemson University, 132 Long Hall, Clemson, SC 29634, USA

Full list of author information is available at the end of the article
}

cnidarians, echinoderms, molluscs, polychaetes, ascidians, and even marine turtles [4-9]. The host-use pattern and population distribution of symbiotic crustaceans also vary widely. For instance, some symbiotic crustaceans inhabit their hosts as solitary individuals: Inachus phalangium (Fabricius, 1775) [10], Petrolisthes spinifrons (H. Milne Edwards, 1837) [11], Ascidonia flavomaculata (Heller, 1864) [12]; in heterosexual pairs: Pinnixa transversalis (H. Milne Edwards \& Lucas, 1842) [13], Alpheus armatus Rathbun, 1901 [14], Pontonia margarita Verrill, 1869 [15]; or in aggregations: Periclimenes anthophilus 
Holthuis \& Eibl-Eibesfeldt, 1964 [16], Petrolisthes mitra (Dana, 1852) [17], Thor amboinensis (De Man, 1888) [18]. Even other symbiotic crustaceans form complex societies i.e., the sponge-dwelling eusocial shrimp Synalpheus regalis Duffy, 1996 [19]. The variety of host-use patterns exhibited by symbiotic crustaceans coupled with disparity in host ecology [20] makes these species excellent models to study the effects of environmental conditions on the social behavior of marine organisms [21-26].

Theoretical and empirical studies suggest that host traits (e.g., abundance, body size, and morphological complexity: $[27,28]$ ), predation risk off hosts [28], interspecific competition for hosts [29], and the host's nutritional value [21] are relevant in explaining the diversity of host use patterns exhibited by symbiotic crustaceans. For instance, Baeza \& Thiel [27] suggested that symbiotic crustaceans should live solitarily or in heterosexual pairs in or on their hosts when the host species is scarce, small (relative to the body size of symbionts), and morphologically simple [27, 28]. Host scarcity determines that the benefits of host monopolization exceed the costs of host defense, and thus, this host trait favors territoriality in symbiotic crustaceans $[27,28]$. Low morphological complexity and small host body size also favor territorial behavior: such hosts are expected to be relatively inexpensive (both in terms of energy and time) to defend against conspecific intruders [27]. By contrast, Baeza and Thiel [27] suggested that symbiotic crustaceans should not be territorial but instead live in aggregations when inhabiting host species reaching high natural abundance and exhibiting complex morphologies and large relative body sizes. The combination of host traits above imply that host guarding behaviors, including patrolling and exclusion of intruders, are energetically too expensive and time consuming $[27,28]$. In general, the probability of symbiotic crustaceans exhibiting host-resource monopolization behavior is expected to decrease with increasing host abundance, host morphological complexity, and relative host size $[5,6,27]$.

In agreement with the theoretical considerations above, various studies conducted during the last decade have reported territorial symbiotic crustaceans living in relatively small, morphologically simple, and naturally scarce host species (e.g., [12, 15, 25-27, 30, 31]). Also in agreement with theory, other symbiotic species live in large non-territorial aggregations in naturally abundant, relatively large and morphologically complex host species $[18,27]$. Although our understanding about the environmental conditions driving the host-use pattern of symbiotic crustaceans has improved considerably during the last decade (e.g., [12, 25]), more studies are needed before major generalizations regarding the mechanisms explaining the social behavior of symbiotic crustacean can be formulated.
The present study explores whether or not symbiotic crustaceans inhabiting large and morphologically complex hosts live in aggregations in or on their host individuals [27]. To explore the notion above, we described the host-use pattern of Periclimenes paivai Chace 1969, a symbiotic palaemonid shrimp that lives in association with Lychnorhiza lucerna Haeckel, 1880, a large and morphologically complex jellyfish.

Periclimenes paivai is a small shrimp (maximum size $=9.2 \mathrm{~mm} \mathrm{CL}$ [carapace length] $-[32-34]$ ), endemic to the western Atlantic coast, and is restricted to shallow waters from Rio de Janeiro to Santa Catarina, Brazil [35, 36]. Periclimenes paivai has been considered a facultative commensal shrimp [33]. However, there are no records of $P$. paivai exhibiting a free-living lifestyle [35, 36]. Periclimenes paivai is the only Brazilian species in the genus found on the surface of scyphozoan jellyfish; Phyllorhiza punctata von Lendenfeld, 1884 (as Mastigias sp.-[32]), L. lucerna, and Chrysaora lactea Eschscholtz, 1829 [33, 34]. Lychnorhiza lucerna is the most abundant rhizostome in the southern Atlantic coast of South America [37], especially in the austral spring and summer, when this jellyfish form blooms [38, 39]. The jellyfish $L$. lucerna measures between 12 and $330 \mathrm{~mm}$ in umbrella diameter and exhibits numerous long and short tentacles [38]. Thus, the jellyfish L. lucerna represents a relatively large and morphologically complex refuge that most likely is difficult (i.e., expensive in terms of time and energy) to monopolize by P. paivai shrimps [27].

Considering the information above, we expect that $P$. paivai should not exhibit territorial behaviors but rather occur as aggregations on host individuals. Limited information suggests that shrimps are indeed often found living in groups in jellyfish [33, 34]. Nonetheless, detailed studies describing group composition, population distribution, and male-female association pattern of this symbiotic species are lacking. Here, we describe the host-use pattern of $P$. paivai, including its population distribution, male-female association pattern, and sexual dimorphism, with the aim of testing the predictions about the absence of territoriality in this species.

\section{Methods}

Sampling of the jellyfish L. lucerna, and its symbiotic shrimp P. pavai, was conducted near the mouth of the Paraíba River estuary $\left(06^{\circ} 58^{\prime} 25^{\prime \prime} \mathrm{S}, 34^{\circ} 51^{\prime} 47^{\prime \prime} \mathrm{W}\right)$, south of Lucena, Paraíba, Brazil. The coast is dominated by mangrove forests in the region [40]. Blooms of scyphozoan medusae, including those formed by the jellyfish $L$. lucerna, periodically occur at the sampling site [41-43]. We used one of this blooms detected during April 09, 2016, to describe the symbiotic relationship between $P$. paivai and its scyphozoan host. 
Specimens of Lychnorhiza lucerna swimming near the surface of the water were randomly collected using a net $($ size of the net mouth $=40 \mathrm{~cm})($ mesh size $=500 \mu \mathrm{m})$ from a canoe ( $3 \mathrm{~m}$ long) equipped with an outboard motor. The selected mesh size impeded the escape of symbiotic shrimps from their host individuals during collections. Each collected medusa was immediately placed into a plastic container full of seawater $(10 \mathrm{~L})$ and measured (MD, maximum diameter) with a caliper to the nearest $0.1 \mathrm{~cm}$. Next, each jellyfish was carefully inspected for specimens of $P$. paivai and all shrimps found in each examined jellyfish were gently removed from their host individuals using forceps, counted, preserved (70\% ethyl alcohol), and stored in separate flasks (one per medusa) for transportation to the Laboratory of Carcinology, Federal University of Sergipe, Sergipe, Brazil.

In the laboratory, the carapace length $(\mathrm{CL})$, the length of the propodus of the major cheliped (MCL), and the width of the pleuron (PW) located in the second abdominal segment (maximum lateral width of the pleuron) of all collected shrimps were measured (accuracy $=0.01 \mathrm{~mm}$ ) under a stereomicroscope (Leica M205 C) using the imaging software Leica Application Suite (LAS) version 4.4. Next, the sex of each shrimp was determined based on the presence (in males) or absence (in females) of appendices masculinae on the base of the endopods of the second pleopods. Lastly, the presence or absence of eggs carried underneath the abdomen by each female shrimp was recorded. Embryos carried by females were classified according to three different categories [44]; stage I: rounded embryos with yolk uniformly distributed, no eye pigments visible, stage II: ovoid embryos, embryos with eye pigments elongated, stage III: ovoid embryos, with well developed eyes and a free pleon.

\section{Population distribution of Periclimenes paivai}

We examined the host use pattern of $P$. paivai, which includes a description of its population distribution, male-female association pattern, and host-shrimp body size relationships. Specifically, we examined whether or not $P$. paivai lives solitarily, in pairs, or in groups in L. lucerna. For this purpose, we determined whether or not the distribution of P. paivai on its jellyfish host (i.e., the frequency of occurrence of hosts without shrimps and with different numbers of shrimps) differed from a random distribution. We compared the observed distribution (i.e., frequency of occurrence of hosts with zero, one, two, three or four shrimps) with the Poisson random distribution [45]. If $P$. paivai exhibits territoriality, then the number of symbiotic guest per host individual should be one (on average) and P. paivai is expected to exhibit a uniform distribution on its host species (see, [25]). By contrast, if $P$. paivai is not territorial, this shrimp should exhibit a random and/or aggregate (contagious) distribution [27].

A number of jellyfish were found to host pairs of shrimps (see results). To determine whether the sexes were randomly distributed among paired shrimps inhabiting the same host individual, the observed distribution of male-male, male-female, and female-female pairs was compared with the Binomial distribution. The expected random frequencies of the different sexes were calculated based on the proportion of males and females recorded for the entire population. A Chi square test of goodness of fit was used to inspect for significant differences between observed and expected (binomial) distributions [46].

\section{Sexual dimorphism and allometry in Periclimenes paivai}

We measured sexual dimorphism in terms of body size and the allometry of specific body parts in P. paivai. We tested whether or not $P$. paivai exhibited sexual dimorphism in body size by comparing the average CL of male and female shrimps using a $t$ test. Moreover, in caridean shrimps from the family Palaemonidae, including representatives from the genus Periclimenes, the second pair of thoracic appendages bears the larger of the two pair of claws $[9,47,48]$. In shrimps, these structures serve as weapons during intra-sexual interactions or for inter-sexual communication [47]. In turn, the pleura of the second abdominal segment are greatly enlarged and help protect the embryos (i.e., from physical abrasion) carried by females beneath their abdomen [47].

To determine sexual dimorphism with respect to the body structures above, we examined whether the largest cheliped on the second pair of pereopods and the pleuron of the second abdominal segment increase linearly with body size in males and females of P. paivai. For this purpose, the relationship between the dependent variables (chela and pleuron) and body size of shrimps (CL) was examined using the allometric model $\mathrm{y}=\mathrm{ax}^{\mathrm{b}}[49$, 50]. The slope $b$ of the log-log least-squares linear regression represents the rate of exponential increase $(b>1)$ or decrease $(b<1)$ of the claw and pleuron segment with a unit of increase in body size of shrimps. To determine if the relationship deviates from linearity, a $t$ test was used to test if the estimated slope $b$ deviates from the expected slope of unity [46]. If the cheliped or the pleuron grows more or less than proportionally with a unit increase in body size of shrimps, then the slope should be greater or smaller than the unity, respectively [49]. Lastly, to test for dissimilarity between males and females with respect to the slopes and intercepts of the lines depicting the relationship between shrimp CL and particular body parts, we used two different General Linear Model (GLM) analyses $(\alpha=0.05)[51]$. 


\section{Results}

A total of 50 specimens of Lychnorhiza lucerna was collected during this study. Jellyfish ranged in maximum diameter between 8.9 and $22 \mathrm{~cm}$ with a mean $( \pm$ standard deviation, SD) of $14.05 \pm 2.83 \mathrm{~cm}$. We found at least one symbiotic shrimp in 36 (72\%) out of the 50 collected jellyfish. Shrimp prevalence was similar in jellyfish ranging in size between 13 and $16 \mathrm{~cm}$ (42\% of the studied jellyfish range in maximum diameter between 13 and $16 \mathrm{~cm}$ ). Shrimps were not present in jellyfish smaller than $10 \mathrm{~cm}$ maximum diameter (Fig. 1). Limited observations during collections indicate that shrimps perch to the subumbrellar region of jellyfish, including the tentacles, and not to the jellyfish ex-umbrellar region.

A total of 64 shrimps were collected during this study. The average number of shrimps per jellyfish ranged between 0 and 4 with a mean ( \pm standard deviation, SD) of $1.28( \pm 1.18)$ shrimp jellyfish ${ }^{-1}$. A positive correlation was observed between jellyfish size and the number of shrimps per jellyfish (analysis including all jellyfish harboring or not shrimps: $\mathrm{F}=10.39, \mathrm{r}^{2}=0.160$, d.f. $=48, P=0.002$; analysis excluding jellyfish not harboring shrimps: $\mathrm{F}=24.85$, $\left.\mathrm{r}^{2}=0.09, d . f .=34, P=0.034\right)$. In addition, a positive correlation was observed between host size and the number of female shrimps found in a single jellyfish $\left(\mathrm{F}=11.75, \mathrm{r}^{2}=0.245, d . f .=32, P=0.001\right)$. However, no significant correlation was found between host size and the number of male shrimps found in a single jellyfish $\left(\mathrm{F}=0.001, \mathrm{r}^{2}=-0.142\right.$, d.f. $\left.=7, P=0.969\right)$.

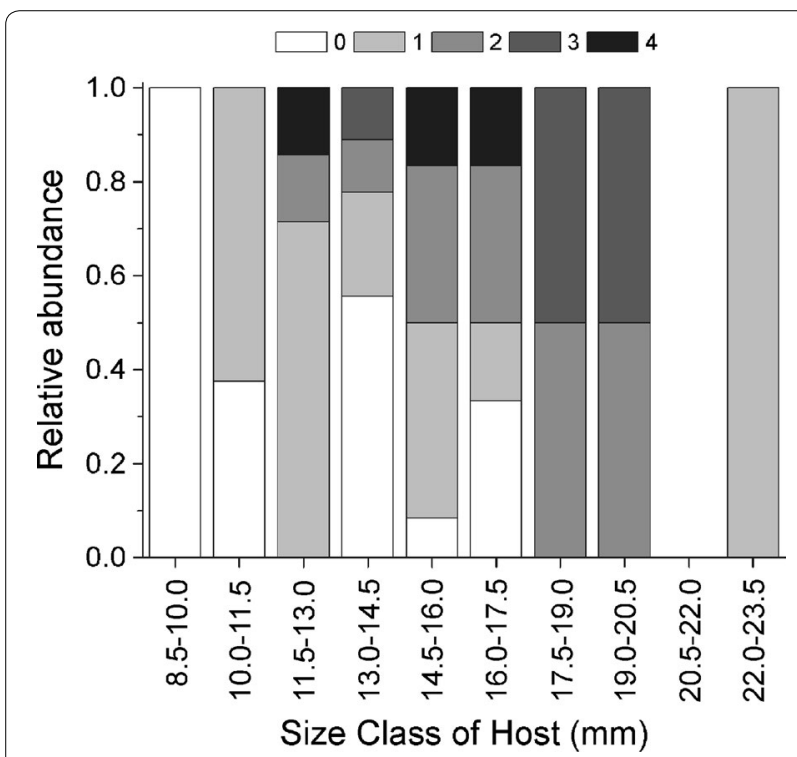

Fig. 1 Relative abundance of Periclimenes paivai per jellyfish host individual belonging to different size classes in Paraíba River estuary, Paraíba, northeastern Brazil
No correlation was observed between host size and shrimp size found in the same jellyfish $(\mathrm{F}=1.154$, $\mathrm{r}^{2}=0.002$, d.f. $=62, P=0.286$ ). In turn, a positive correlation was observed between host size and the largest shrimp found in a single jellyfish $\left(\mathrm{F}=6.798, \mathrm{r}^{2}=0.142\right.$, d.f. $=34, P=0.013)$.

The population distribution of $P$. paivai in the jellyfish $L$. lucerna did not differ significantly from a random Poisson distribution (Chi square test of goodness-offit, $x^{2}=0.34, d . f .=2, P=0.84$; Fig. 2a). A total of 19 $(38 \%)$ jellyfish hosted a single shrimp. Eighteen out of these 19 solitary shrimps were females, and $77.7 \%$ of these solitary females $(\mathrm{N}=14)$ carried eggs underneath the abdomen $(7,3$, and 4 females carried early, intermediate and late eggs, respectively). Sex ratio differed from a random binomial distribution among solitary shrimps (males:females $=1: 18$; binomial test, $P<0.001$ ). The average diameter of those jellyfish harboring a single female $(13.57 \pm 2.81)$ was smaller than that of jellyfish hosting two or more female shrimps $(16.35 \pm 2.04)(t$ test: $t=4.03, d . f .=48, P=0.0002)$.

A total of 10 (20\%) jellyfish hosted two shrimps. Three and seven jellyfish hosted male-female and femalefemale pairs, respectively. No male-male pairs were observed. Paired shrimps were found as homosexual and heterosexual pairs as often as expected by chance alone (observed frequency distribution vs expected binomial distribution: $X^{2}=2.487$, d.f. $=2, P=0.28$; Fig. 2b). In these jellyfish harboring only two shrimps, the observed sex ratio was also biased toward females (males:females $=3: 17$; binomial test, $P<0.001$ ).

A total of three jellyfish harbored three shrimps; two jellyfish each hosted three ovigerous females (Host \# 11 and 12; Fig. 3a) and one jellyfish harbored three males (Host \# 13; Fig. 3a). Four jellyfish hosted four shrimps (Host \# 14, 15, 16 and 17; Fig. 3a) and no jellyfish hosted 5 or more shrimps (Fig. 3a). In jellyfish hosting three or more shrimps, the sex ratio of $P$. paivai was not statistically significant from an expected 1:1 sex ratio (binomial test, $P=0.32$ ).

A two-way ANOVA did not demonstrate an effect of group size (solitary, paired, trios or quartets) in shrimp body size $(\mathrm{F}=0.42$, d.f. $=3, P=0.74)$. However, sex did affect shrimp CL $(\mathrm{F}=12.61, d . f .=1, P<0.001)$. The interaction term in this ANOVA was statistically significant $(\mathrm{F}=631.90$, d.f. $=1, P<0.001)$ (Fig. 3b).

\section{Sexual dimorphism in Periclimenes paivai}

The CL of male and female shrimps varied between 2.61 and $3.93 \mathrm{~mm}$ (mean $\pm \mathrm{SD}, 3.24 \pm 0.46$ ) and between 2.11 and $5.51 \mathrm{~mm}$ (4.29 \pm 0.86$)$, respectively (Fig. 4a). Females attain larger average and final body sizes than males in Periclimenes paivai $(\mathrm{t}=4.20$, d.f. $=61, P<0.001)$. 


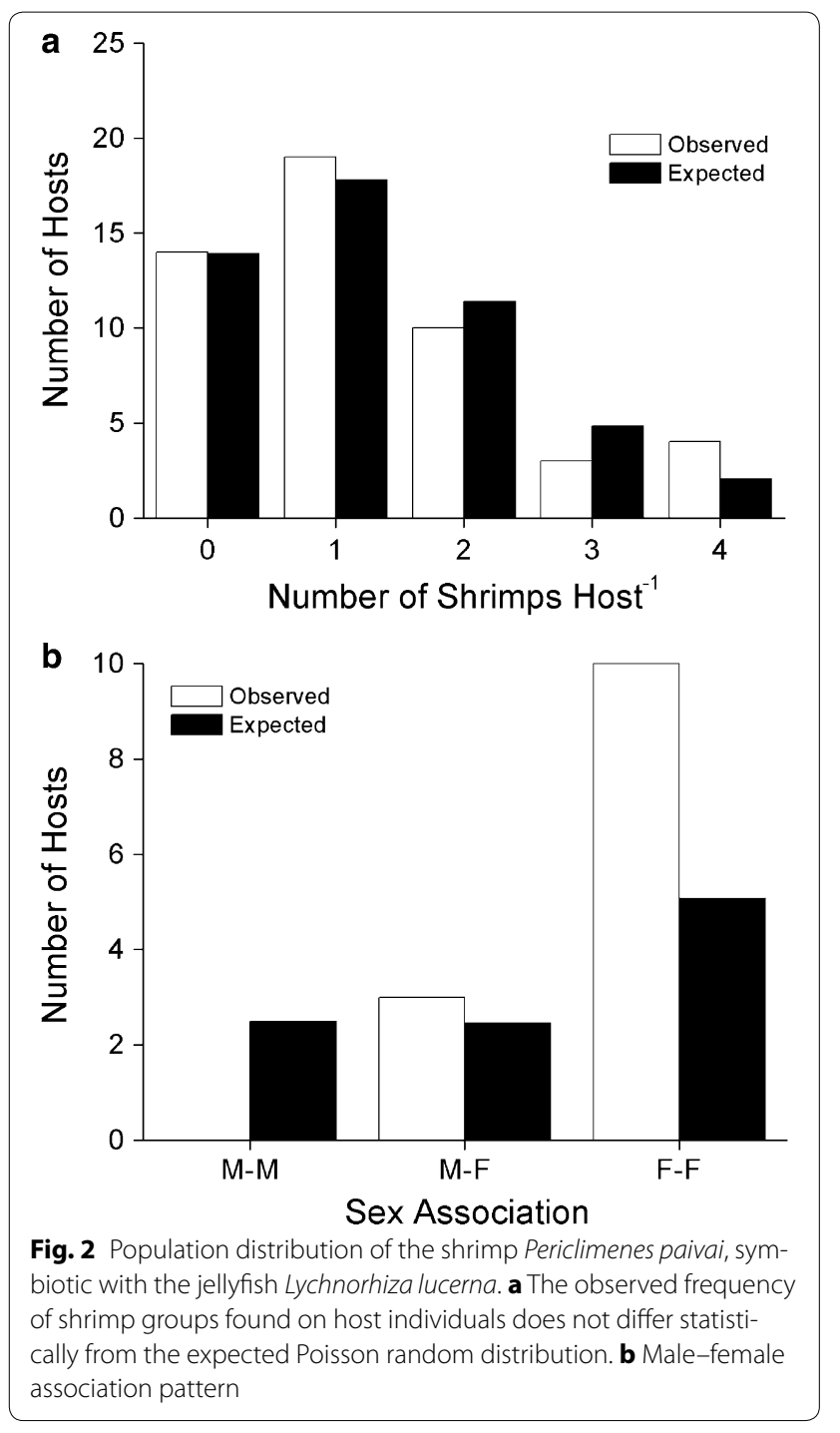

A positive correlation was detected between $\mathrm{CL}$ and the length of the propodus of the major cheliped in shrimps of the two sexes, as well as between CL and the width of the pleuron of the second abdominal segment in the two sexes (Table 1 and Fig. $4 \mathrm{~b}, \mathrm{c}$ ). In males, the growth of the claw was isometric with respect to $C L$; the slope of the relationship between male CL and claw length did not differ significantly from unity $(b=1.02, P>0.05)$. In females, the growth of the claw was positively allometric with respect to $\mathrm{CL}(\mathrm{b}=1.64, P<0.01)$. A GLM analysis demonstrated no significant effect of $\operatorname{sex}(\mathrm{F}=1.97, d . f .=1,58$, $P=0.16$ ), but demonstrated an effect of $C L$ in claw length $(\mathrm{F}=98.76, d . f .=1,58, P<0.001)$. Furthermore, the interaction term of this analysis was significant $(\mathrm{F}=5.35$, $d . f .=1,58, P=0.02)$. Therefore, the absolute size of the claw and the growth rate of this structure were greater in females than in males of P. paivai (Table 1 and Fig. 4b).
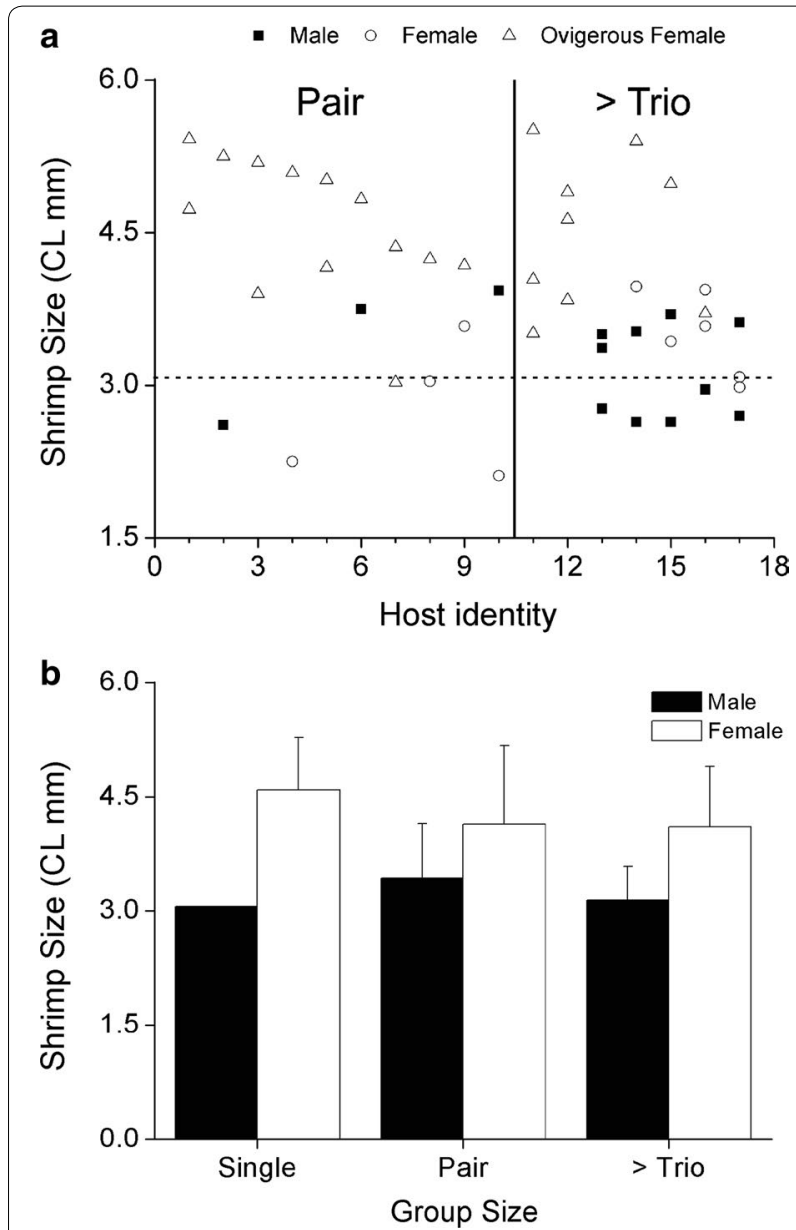

Fig. 3 Sex and carapace width of Periclimenes paivai. a Shrimps living in groups $(\mathrm{N}>2$ ) on the surface of the jellyfish Lychnorhiza lucerna for different group sizes. The dashed line indicates the size of the smallest ovigerous female. $\mathbf{b}$ Body size (CW, mean \pm standard deviation [vertical bars]) of male and female shrimps present in different groups

In males, the growth of the pleuron of the second abdominal segment was isometric; the slope was not significantly different from the unity $(b=0.62, P>0.05)$. In females, the same structure exhibited positive allometry ( $\mathrm{b}=1.55, P<0.01)$. A GLM analysis indicated a significant effect of sex in pleuron width $(\mathrm{F}=4.95, d . f .=1,60$, $P=0.03)$. The GLM analysis also detected an effect of CL in pleuron width $(\mathrm{F}=33.27$, d.f. $=1,60, P<0.01)$, and the interaction term was significant $(\mathrm{F}=6.02, d . f .=1$, $60, P=0.01$ ). Thus, the absolute size of the second pleuron and the growth rate of this structure were greater in females than in males of P. paivai (Table 1 and Fig. 4c).

\section{Discussion}

In this study, host abundance, relative body size, and morphological complexity were expected to favor group living and to constrain territoriality (and solitariness) in $P$. 

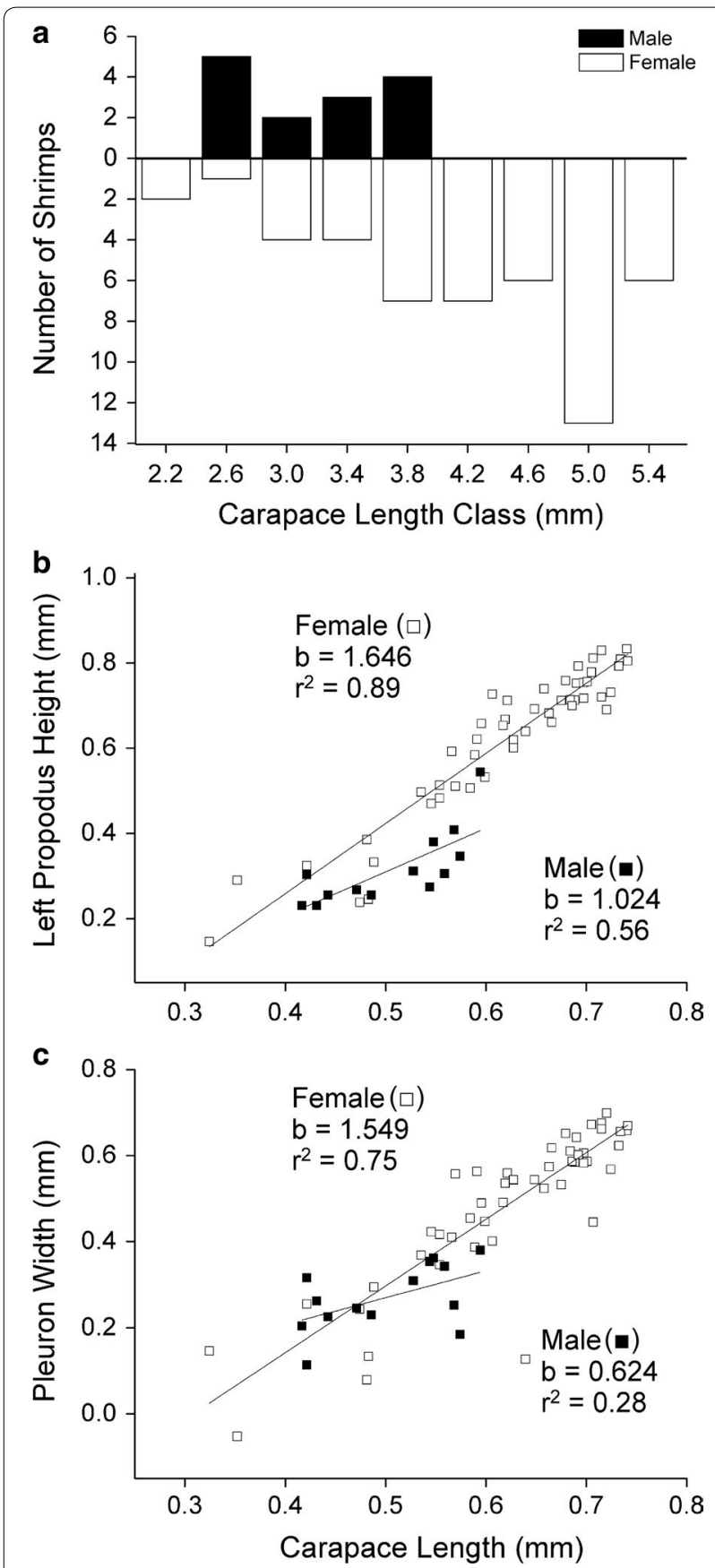

Fig. 4 Sexual dimorphism in Periclimenes paivai, symbiotic with the jellyfish Lychnorhiza lucerna. a Size frequency distribution (CL) in male and female shrimps. $\mathbf{b}$ Relative growth of the length of the propodus of the major cheliped as a function of carapace length. $\mathbf{c}$ Relative growth of the width of the pleuron of the second abdominal segment as a function of carapace width. Linear regression equations obtained after log-log transformation of the data are shown for each sex in Table 1 paivai. In agreement with the idea that host traits should favor group living in $P$. paivai, the population distribution of this symbiotic shrimp in the jellyfish L. lucerna did not differ significantly from a random Poisson distribution. The random population distribution of $P$. paivai on the jellyfish L. lucerna agrees with that reported for other ectosymbiotic crustaceans that are not territorial and live in aggregations on their host individuals (caridean shrimps: Ancylomenes pedersoni (Chace, 1958) [52], Periclimenes antipathophilus Spotte, Heard \& Bubucis, 1994 [53], Periclimenes patae Heard \& Spotte, 1991 [54] and Thor amboinensis [18]; other crustaceans: Petrolisthes mitra [6], and Dissodactylus primitivus Bouvier, 1917 [21]). Our observations also agree with previous studies conducted in other localities that have reported $P$. paivai living gregariously on the surface of the same or a different host species (e.g., [33, 34]). By contrast to that observed in P. paivai, territorial species display a uniform population distribution and live solitarily (or in male-female pairs) in/on their respective host species with a frequency greater than expected by chance alone $[25,27,55]$.

The population distribution of $P$. paivai also differs from that reported before in symbiotic shrimps that exhibit a socially monogamous mating system. In socially monogamous symbiotic crustaceans, the population distribution also differs from a random Poisson distribution and host individuals harbor male-female pairs of symbiotic crustaceans either invariably [56] or with a frequency much greater than expected by chance alone $[15,26,31,57]$. Furthermore, there is often a tight correlation between the body size of male and female symbiotic individuals living in pairs and the body size of symbiotic individuals is tightly correlated with that of the host individuals harboring them [13, 15, 26, 31]. Most often, growth restrictions imposed by host individuals over their long-term resident monogamous symbiotic organisms is invoked to explain such host-shrimp and male-female shrimp body size relationships [15 and references therein). By contrast to that reported for socially monogamous species, in P. paivai, only $20 \%$ of the examined jellyfish hosted only two shrimps, shrimp pairs were not always heterosexual, and the frequency of these pairs was not greater than expected by chance alone. Furthermore we did not observe a tight relationship between individuals forming heterosexual pairs and between $P$. paivai shrimps and the jellyfish harboring them (results not shown due to the same small number of male-female pairs observed, $\mathrm{N}=3$ ). The above argue against the notion that $P$. paivai is a socially monogamous species. 
Table 1 Relative growth of selected structures in males and females of Periclimenes paivai

\begin{tabular}{|c|c|c|c|c|c|c|c|c|c|}
\hline Sex & y & $\mathbf{x}$ & Regression & $r^{2}$ & SE & $\mathbf{t}$ & $P$ & Allometry & Sexual dimorphism \\
\hline Male & MCL & $\mathrm{CL}$ & $y=1.0247 x-0.2027$ & 0.560 & 0.2738 & 3.742 & $>0.05$ & 0 & Female > Male \\
\hline Female & $\mathrm{MCL}$ & $\mathrm{CL}$ & $y=1.6467 \times-0.4002$ & 0.897 & 0.0812 & 20.267 & $<0.001$ & + & \\
\hline Male & PW & $\mathrm{CL}$ & $y=0.6246 x-0.0423$ & 0.282 & 0.2874 & 2.173 & $>0.05$ & 0 & Female > Male \\
\hline Female & PW & $\mathrm{CL}$ & $y=1.549 x-0.4778$ & 0.755 & 0.1274 & 12.167 & $<0.001$ & + & \\
\hline
\end{tabular}

$0=$ isometry $+=$ positive allometry; $\mathrm{r}^{2}=$ determination coefficient; $\mathrm{CL}=$ carapace length; $\mathrm{MCL}=$ major cheliped length; $\mathrm{PW}=$ pleuron width

Overall, the population distribution of Periclimenes paivai suggests that this species is not territorial (at least males). Periclimenes paivai most often lives in small groups of 2-4 individuals on the surface of its jellyfish host L. lucerna. In this study, we have hypothesized that host traits drive gregariousness in symbiotic crustaceans. The jellyfish L. lucerna was suggested to represent a large and morphologically complex refuge that was too expensive to defend, both in terms of time and energy, by a single or a small group (pairs) of shrimps. In agreement with the idea that the jellyfish L. lucerna is a host difficult to defend against intruders, the quotient between host and shrimp body size was $\sim 25$ (calculation based on the average-size jellyfish (14 $\mathrm{cm}$ diameter) and the largest shrimp (5.51 $\mathrm{mm} \mathrm{CL}$ ) observed during our study). We understand that the above ratio is a raw measure of space available to shrimps within a host individual $[18,27]$. Still, this number suggests that a single jellyfish is able to harbor a large number of shrimps at the same time, and thus, turns host-monopolization into an unfeasible strategy in this symbiotic species.

Importantly, in P. paivai, females exhibit larger claws than males at any given body size and females, but not males, experience positive allometry in cheliped size. The pattern of sexual dimorphism herein reported for $P$. paivai argues in favor of territoriality in females (but not males) or, at least, suggests that females might be competing for resources (i.e., food) likely expected to impact (considerably) their reproductive output. Positive allometric growth in claws has been reported before in Petrolisthes spinifrons, a porcelain crab in which the two sexes defend 'their' host individuals against conspecific intruders $[11,30]$. Additional support for the notion of territoriality in females, but not necessarily males, is the frequent finding of solitary females of $P$. paivai inhabiting small but not large host in the natural environment. It must be noticed, however, that the observed frequency of solitary females was not greater than expected by chance alone. The presence of solitary females in small but not large jellyfish can be explained if females are capable of excluding other females from 'their' host individuals via territorial aggression when jellyfish are small. When hosts attain larger body sizes, however, females might not effectively monopolize a single host individual against other females. The positive relationship between host size and female number also supports the notion above. Overall, although the host-use pattern herein reported for $P$. paivai suggests that males are not territorial, the large body size, large chelipeds, and positive allometry in weaponry (claws) suggest that females might exhibit territorial behaviors to some extent. Studies on the life history (including life expectancy) of jellyfish and shrimps as well as direct observations on shrimp female-female interactions and activity patterns are needed to test the notion of territoriality and solitary living in females of $P$. paivai.

\section{Implications for the mating system of Periclimenes paivai}

In Periclimenes paivai, males are neither territorial nor engage in social monogamy, by contrast to that reported for many other symbiotic crustaceans [20]. What is the mating system of the gregarious $P$. paivai? Our study suggests that host morphological complexity constrains the evolution of territoriality in males (but not necessarily females, see above) of $P$. paivai. Mating systems can be characterized by the mating strategies used by males in the population [58]. In turn, male mating strategies strongly depend on the environmental potential for monopolization of females and/or resources (hosts) to attract them [28, 58]. Given the infeasibility of host monopolization, males should attempt to increase mating opportunities by using exploitative (e.g., 'pure-search') rather than interference (e.g., territorial) mating tactics $[28,47,59]$. This 'pure-search' behavior is expected to favor small body size and weapons (e.g., claws) in males because that leads to an increase in agility and encounter rates with receptive females $[28,47,58]$. Supporting the idea of a pure-search mating system in $P$. paivai, males were much smaller than females, and these males did not exhibit well developed claws used as weapons to fight for females [60]. Our results agree with the idea that $P$. paivai features a pure-search mating system.

The common observation of solitary females brooding embryos (in different stages of development) and the female-skewed sex ratio also support the notion of a puresearch mating system in males of $P$. paivai. In caridean 
shrimps, including P. paivai, females do not store sperm and need to be inseminated short after molting to fertilize a new batch of eggs [47]. Thus, if males of $P$. paivai were not roaming around, switching among host individuals in search of receptive females rather frequently, then the observation of solitary females brooding embryos would be difficult to explain. Also, in P. paivai, sex specific differences in mortality rates by predators, driven by a greater propensity of males (compared to females) to switch among host individuals (see above), could lead to the observed sex ratio being skewed towards females in the population. Female-skewed sex ratios have been reported before in other symbiotic and free-living crustaceans in which males frequently roam among hosts in search of receptive females $[12,61]$. By contrast to that reported for $P$. paivai, the sex ratio is hardly ever skewed in favor of females in populations of symbiotic crustaceans that do not or rarely switch among host individuals, and that exhibit a monogamous mating system $[15,26,31]$.

Overall, our results, albeit limited, suggest that $P$. paivai features a pure-search promiscuous mating system with putatively roaming males and territorial females. Nonetheless, our data does not reveal to us the most important details about the species's reproductive behavior. We do not know (1) if shrimps (in particular, females) exhibit territorial behaviors, (2) if males switch hosts in search of females, (3) if predation risk impacts male mating strategies (i.e., host switching) and thus drives the observed female-skewed sex ratio, and (4) if females exhibit passive or active mate choice. We argue in favor of additional experimental studies focusing on describing the mating behavior of P. paivai in the laboratory and the movement patterns of individuals in the field to test the hypothesis that $P$. paivai features a pure-search mating system. Furthermore, additional studies need to determine the time of host colonization by P. paivai. Likely, this symbiotic shrimp colonizes host individuals during larval settlement as reported before for other symbiotic crustaceans [20] Whether or not water-borne chemical cues are used by settling stages to locate host individuals remains to be addressed.

This study has improved our understanding about environmental conditions driving the host-use pattern, social behavior, and mating system of resource-specialist (i.e., symbiotic) marine invertebrates. The family Palaemonidae, to which P. paivai belongs, is a specious clade of crustaceans with great disparity in terms of ecology; some species are free-living, others live on the surface of cnidarians (this study), and even other species reside in the gill chamber of mollusks [62 and references therein]. Shrimps belonging to the family Palaemonidae could be used as a model system to explore the role of the environment in driving the mating systems of marine organisms.

\section{Abbreviations}

ANOVA: Analysis of variance; CL: Carapace length; GLM: General linear model; MCL: Major cheliped length; MD: Maximum diameter; LAS: Leica Application Suite; PW: Pleuron width; SD: Standard deviation.

\section{Authors' contributions}

$J A B$ conducted writing of the paper, the data analysis and literature review; SPB-A and DFRA conducted writing of the paper, the identification and measurement of shrimps, the data analysis and literature review; RAL and SFBL carried out the sampling work, the identification of jellyfish and reviewed the manuscript. All authors read and approved the final manuscript.

\section{Author details \\ ${ }^{1}$ Department of Biological Sciences, Clemson University, 132 Long Hall, Clem- son, SC 29634, USA. ${ }^{2}$ Smithsonian Marine Station at Fort Pierce, 701 Seaway Drive, Fort Pierce, FL 34949, USA. ${ }^{3}$ Departamento de Biología Marina, Facultad de Ciencias del Mar, Universidad Católica del Norte, Larrondo 1281, Coquimbo, Chile. ${ }^{4}$ Laboratório de Carcinologia, Universidade Federal de Sergipe, UFS, São Cristóvão, Sergipe, Brazil. ${ }^{5}$ Group of Studies on Crustacean Biology, Ecology and Culture - NEBECC, Botucatu, São Paulo, Brazil. ${ }^{6}$ Universidade Federal da Paraíba - Campus I, Departamento de Sistemática e Ecologia, Programa de Pós-Graduação em Ciências Biológicas, Cidade Universitária, João Pessoa, Paraíba 58051-900, Brazil. ${ }^{7}$ Universidade Federal de Campina Grande, Centro de Formação de Professores, Unidade Acadêmica de Ciências Exatas e da Natureza, Rua Sérgio Moreira de Figueiredo, Casas Populares, Cajazeiras, Par- aíba 58900-000, Brazil. ${ }^{8}$ Universidade Federal da Paraíba - Campus II, Departa- mento de Ciências Biológicas, Programa de Pós-Graduação em Biodiversidade, Cidade Universitária, Areia, Paraíba 58397-000, Brazil.}

Acknowledgements

All sampling in this study was conducted according to applicable state and federal laws.

\section{Competing interests}

The authors declare that they have no competing interests.

\section{Availability of data and materials}

The datasets generated and/or analyzed during the current study are available in Laboratório de Carcinologia, Universidade Federal de Sergipe, UFS, São Cristóvão, Sergipe under responsibility of D.F.R. Alves.

Consent for publication

Not applicable.

Ethics approval and consent to participate

All applicable international, national, and/or institutional guidelines for the care and use of animals were followed.

\section{Funding}

No funding was received to conduct this study.

\section{Publisher's Note}

Springer Nature remains neutral with regard to jurisdictional claims in published maps and institutional affiliations.

Received: 6 June 2017 Accepted: 26 September 2017

Published online: 10 October 2017

\section{References}

1. Martin JW, Davis GE. An updated classification of the recent Crustacea. Los Angeles: Science Series 39, Natural History Museum of Los Angeles Country; 2001.

2. De Grave S, Pentcheff ND, Ahyong ST, Chan TY, Crandall KA, Dworschak PC, Felder DL, Feldmann RM, Fransen CHJM, Goulding LYD, Lemaitre R, Low MEY, Martin JW, Ng PKL, Schweitzer CE, Tan SH, Tshudy D, Wetzer R. A classification of living and fossil genera of decapod crustaceans. Raffles Bull Zool. 2009;Suppl 21:1-109. 
3. De Bary HA. Die erscheinung der symbiose. In: Trübner von Karl J, editor. Vortrag auf der versammlung der naturforscher und ärtza zu cassel. Strasbourg: Verlag; 1879. p. 1-30.

4. Ross DM. Symbiotic relations. In: Vernberg SJ, Vernberg WB, editors. The biology of crustacea 7. New York: Academic Press; 1983. p. 163-212.

5. Thiel M, Baeza JA. Factors affecting the social behaviour of symbiotic Crustacea: a modelling approach. Symbiosis. 2001;30:163-90.

6. Thiel M, Zander A, Baeza JA. Movements of the symbiotic crab Liopetrolisthes mitra between its host sea urchin Tetrapygus niger. Bull Mar Sci. 2003;72:89-101.

7. Wirtz P, Melo GAS, Grave S. Symbioses of the decapod crustaceans along the coast of Espírito Santo, Brazil. Mar Biodivers Rec. 2009;2:1-9. doi:10.1017/S175526720999087X.

8. Lima SFB, Queiroz V, Bravo de Laguna IH, Mioso R. New host for Dissodactylus crinitichelis (Decapoda, Pinnotheridae): first record of occurrence on Mellita quinquiesperforata (Echinodermata, Echinoidea) (Decapoda; Echinodermata). Spixiana. 2014;37:61-8.

9. Baeza JA, Hemphill CA, Ritson-Williams R. The sexual and mating system of the shrimp Odontonia katoi (Palaemonidae, Pontoniinae), a symbiotic guest of the ascidian Polycarpa aurata in the coral triangle. PLoS ONE. 2015. doi:10.1371/journal.pone.0121120.

10. Diesel R. Optimal mate searching strategy in the symbiotic spider crab Inachus phalangium (Decapoda). Ethology. 1986;72:311-28. doi:10.1111/j.1439-0310.1986.tb00632.x.

11. Baeza JA, Thiel M, Stotz WB. The life history of Allopetrolisthes spinifrons, a crab associate of the sea anemone Phymactis clematis. J Mar Biol Assoc UK. 2001;81:69-76.

12. Baeza JA, Díaz-Valdés M. The symbiotic shrimp Ascidonia flavomaculata lives solitarily in the tunicate Ascidia mentula: implications for its mating system. Invertebr Biol. 2011;130:351-61. doi:10.1111/j.1744-7410.2011.00244.x.

13. Baeza JA. Indicators of monogamy in the commensal crab Pinnixa transversalis (Milne Edwards \& Lucas) (Decapoda: Brachyura: Pinnoteridae): population distribution, male-female association and sexual dimorphism. Rev Biol Mar Oceanogr. 1999;34:303-13.

14. Knowlton N. Sexual selection and dimorphism in two demes of a symbiotic, pair-bonding snapping shrimp. Evolution. 1980;34:161-73. doi:10.2307/2408325.

15. Baeza JA. Social monogamy in the shrimp Pontonia margarita, a symbiont of Pinctada mazatlantica, in the tropical eastern Pacific coast. Mar Biol. 2008;153:387-95. doi:10.1007/s00227-007-0815-9.

16. Nizinski MS. Ecological distribution, demography and behavioral observations on Periclimenes anthophilus, an atypical symbiotic cleaner shrimp. Bull Mar Sci. 1989;45:174-88.

17. Baeza JA, Thiel M. Host use pattern and life history of Liopetrolisthes mitra, an associate of the black sea urchin Tetrapygus niger. J Mar Biol Assoc UK. 2000;80:39-45.

18. Baeza JA, Piantoni C. Sexual system, sex ratio and group living in the shrimp Thor amboinensis (De Man): relevance to resource-monopolization and sex-allocation theories. Biol Bull. 2010;219:151-65.

19. Duffy JE. Eusociality in a coral-reef shrimp. Nature. 1996;381:512-4. doi:10.1038/381512a0.

20. Baeza JA. Crustaceans as symbionts: an overview of their diversity, host use and life styles. In: Watling L, Thiel M, editors. The life styles and feeding biology of the crustacea. Oxford: Oxford University Press; 2015. p. 163-89.

21. De Bruyn C, Rigaud T, Bruno D, Ridder C. Symbiosis between the pea crab Dissodactylus primitivus and its echinoid host Meoma ventricosa: potential consequences for the crab mating sytem. Mar Ecol Prog Ser. 2009;375:173-83. doi:10.3354/meps07733.

22. Ocampo EH, Nuñez JD, Cledón M, Baeza JA. Host-specific reproductive benefits, host selection behavior and host use pattern of the pinnotherid crab Calytraeotheres garthi. J Exp Mar Biol Ecol. 2012;429:36-46. doi:10.1016/j.jembe.2012.06.009.

23. Ory NC, Dudgeon, Thiel M. Host-use patterns and factors influencing the choice between anemone and urchin hosts by a caridean shrimp. J Exp Mar Biol Ecol. 2013;449:85-92. doi:10.1016/j.jembe.2013.09.002.

24. Jossart Q, Wattier RA, Kastally C, Aron S, David B, Ridder CD, Riguad T. Genetic evidence confirms polygamous mating system in a crustacean parasite with multiple hosts. PLOS ONE. 2014. doi:10.1371/journal. pone.0090680.
25. Ambrosio LJ, Baeza JA. Territoriality and conflict avoidance explain asociality (Solitariness) of the endosymbiotic pea crab Tunicotheres moseri. PLoS ONE. 2016. doi:10.1371/journal.pone.0148285.

26. Baeza JA, Simpson L, Ambrosio LJ, Guéron R, Mora N. Monogamy in a Hyper-Symbiotic Shrimp. PLoS ONE. 2016. doi:10.1371/journal. pone.0149797.

27. Baeza JA, Thiel M. Predicting territorial behavior in symbiotic crabs using host characteristics: a comparative study and proposal of a model. Mar Biol. 2003;142:93-100. doi:10.1007/s00227-002-0927-1.

28. Baeza JA, Thiel M. The mating system of symbiotic crustaceans. A conceptual model based on optimality and ecological constraints. In: Duffy JE, Thiel M, editors. Reproductive and social behavior: crustaceans as model systems. Oxford: Oxford University Press; 2007. p. 245-55.

29. Baeza JA. The symbiotic lifestyle and its evolutionary consequences: social monogamy and sex allocation in the hermaphroditic shrimp Lysmata pederseni. Naturwissenschaften. 2010;97:729-41. doi:10.1007/ s00114-010-0689-4 (PMID:20552156).

30. Baeza JA, Stotz W, Thiel M. Agonistic behavior and development of territoriality during ontogeny of the sea anemone dwelling crab Allopetrolisthes spinifrons (H. Milne Edwards, 1837) (Decapoda: Anomura: Porcellanidae). Mar Fresh Behav Physiol. 2002;35(4):189-202. doi:10.1080/10236240 21000003817.

31. Baeza JA, Bolaños JA, Hernandez JE, Lira C, López R. Monogamy does not last long in Pontonia mexicana, a symbiotic shrimp of the amber penshell Pinna carnea from the southeastern Caribbean Sea. J Exp Mar Biol Ecol. 2011;407:41-7. doi:10.1016/j.jembe.2011.07.011.

32. Chace FA. A new genus and five new species of shrimps (Decapoda, Palaemonidae, Pontoniinae) from the western Atlantic. Crustaceana. 1969;16:251-72. doi:10.1163/156854069X00295.

33. Martinelli Filho JE, Stampar SN, Morandini AC, Mossolin EC. Cleaner shrimp (Caridea: Palaemonidae) associated with scyphozoan jellyfish. Vie Milieu. 2008;58:133-40.

34. Gonçalves GRL, Wolf MR, Costa RC, Castilho AL. Decapod crustacean associations with scyphozoan jellyfish (Rhizostomeae: Pelagiidae) in the Southeastern Brazilian coast. Symbiosis. 2016. doi:10.1007/ s13199-016-0395-x.

35. Ramos-Porto M, Coelho PA. Malacostraca. Eucarida. Caridea (Alpheoidea excluded). In: Young PS, editor. Catalogue of Crustacea of Brazil. Rio de Janeiro: Museu Nacional; 1998. p. 325-50.

36. Pantaleão JA, Carvalho-Batista A, Fransozo A, Costa RC. The influence of upwelling on the diversity and distribution of marine shrimp (Penaeoidea and Caridea) in two tropical coastal areas of southeastern Brazil. Hydrobiologia. 2016;763:381-95. doi:10.1007/s10750-015-2429-4.

37. Mianzan HW. Estudio sistemático y bioecológico de algunas medusas Scyphozoa de la región subantártica. La Plata: Universidad Nacional de La Plata; 1986.

38. Nogueira M Jr, Haddad MA. Lychnorhiza lucerna Haeckel (Scyphozoa, Rhizostomeae) and Libinia ferreirae Brito Capello (Decapoda, Majidae) association in southern Brazil. Rev Bras Zool. 2005;22:908-12. doi:10.1590/ S0101-81752005000400015.

39. Sal Moyano MP, Schiariti A, Gilberto DA, Diaz Briz L, Gavio MA, Mianzan HW. The symbiotic relationship between Lychnorhiza lucerna (Scyphozoa, Rhizostomeae) and Libinia spinosa (Decapoda, Epialtidae) in the Río de La Plata (Argentina-Uruguay). Mar Biol. 2012;159:1933-41. doi:10.1007/ s00227-012-1980-z.

40. Sassi R. Phytoplankton and environmental factors in the Paraíba do Norte River Estuary, northeastern Brazil: composition, distribution and quantitative remarks. Bolm Inst Oceanogr. 1991;39:93-115.

41. Peterson RG, Stramma L. Upper-level circulation in the South Atlantic Ocean. Prog Oceanogr. 1991;26:1-73. doi:10.1016/0079-6611(91)90006-8.

42. Genin A, Jaffe JS, Reef R, Richter C, Franks PJS. Swimming against the flow: a mechanism of zooplankton aggregation. Science. 2005;308:860-2. doi:10.1126/science.1107834.

43. Gusmão LMO, Díaz XFG, Melo M Jr, Schwamborn R, Neumann-Leitão S. Jellyfish diversity and distribution patterns in the tropical Southwestern Atlantic. Mar Ecol. 2014. doi:10.1111/maec.12119.

44. Wehrtmann IS. Distribution and reproduction of Ambidexter panamense and Palaemonetes schmitti in Pacific Costa Rica (Crustacea, Decapoda). Rev Biol Trop. 1990;38:327-9.

45. Elliott JM. Some methods for the statistical analysis of samples of benthic invertebrates. 3rd ed. Far Sawrey: Freshwater Biological Association; 1983. 
46. Sokal RR, Rohlf FJ. Biometry. 3rd ed. San Francisco: W.H. Freeman; 1981

47. Bauer RT. Remarkable shrimps. Norman: Oklahoma University Press; 2004

48. Fransen CHJM. On Pontoniinae (Crustacea, Decapoda, Palaemonidae) collected from ascidians. Zoosystema. 2006;28:713-46.

49. Hartnoll RG. The determination of relative growth in Crustacea. Crustaceana. 1978;34(3):281-93. doi:10.1163/156854078X00844.

50. Hartnoll RG. Growth. In: Bliss DE, Abele LG, editors. The Biology of Crustacea, 2, embryology, morphology and genetics. New York: Academic Press; 1982. p. 111-96.

51. Zar JH. Biostatistical analysis. 5th ed. Upper Saddle River: Prentice-Hall; 2010.

52. Limbaugh C, Pederson H, Chace FA Jr. Shrimps that clean fishes. Bull Mar Sci Gulf Carib. 1961;11:237-57.

53. Spotte SR, Heard W, Bubucis PM. Pontoniine shrimps (Decapoda: Caridea: Palaemonidae) of the northwest Atlantic. IV. Periclimenes antipathophilus new species, a black coral associate from the Turks and Caicos Islands and eastern Honduras. Bull Mar Sci. 1994;55:212-27.

54. Heard RW, Spotte S. Pontoniine shrimps (Decapoda: Caridea: Palaemonidae) of the northwest Atlantic. II. Periclimenes patae, new species, a gorgonian associate from shallow reef areas off the Turks and Caicos Islands and Florida Keys. Proc Biol Soc Wash. 1991;104:40-8.

55. Castro P. Settlement and habitat selection in the larvae of Echinoecus pentagonus (A. Milne Edwards), a brachyuran crab symbiotic with sea urchins. J Exp Mar Biol Ecol. 1978;34:259-70. doi:10.1016/S0022-0981(78)80007-0.

56. Aucoin S, Himmelman JH. A first report on the shrimp Pontonia sp. and other potential symbionts in the mantle cavity of the penshell Pinna carnea in the Dominican Republic. Symbiosis. 2010;50:135-41. doi:10.1007/ s13199-010-0050-x
57. Pfaller JB, Alfaro-Shigueto J, Giffoni B, Ishihara T, Mangel JC, Peckham $\mathrm{SH}$, Bjorndal KA, Baeza JA. Social monogamy in the crab Planes major, a facultative symbiont of loggerhead sea turtles. J Exp Mar Biol Ecol. 2014;461:124-32. doi:10.1016/j.jembe.2014.08.011.

58. Shuster SM, Wade MJ. Mating systems and strategies. Princeton: Princeton University Press; 2003.

59. Bauer RT, Abdalla JH. Male mating tactics in the shrimp Palaemonetes pugio (Decapoda, Caridea): precopulatory mate guarding vs. pure search. Ethology. 2001;107:185-99. doi:10.1046/j.1439-0310.2001.00636.x.

60. Baeza JA, Bauer RT, Okuno J, Thiel M. Molecular phylogeny of hinge-beak shrimps (Decapoda: Caridea: Rhynchocinetes and Cinetorhynchus) and allies: a formal test of familiar and generic monophyly using a multilocus phylogeny. Zool J Linn Soc. 2014;172:426-50. doi:10.1111/zoj.12173.

61. Hernández JE, Bolaños JA, Palazón JL, Hernández G, Lira C, Baeza JA. The enigmatic life history of the symbiotic crab Tunicotheres moseri (Crustacea, Brachyura, Pinnotheridae): implications for its mating system and population structure. Biol Bull. 2012;223:278-90. doi:10.1086/ BBLV223n3p278.

62. Horká I, De Grave S, Fransen CHJ, Petrusek A, Ďuriš Z. Multiple host switching events shape the evolution of symbiotic palaemonid shrimps (Crustacea: Decapoda). Sci Rep. 2016. doi:10.1038/srep26486.

\section{Submit your next manuscript to BioMed Central and we will help you at every step:}

- We accept pre-submission inquiries

- Our selector tool helps you to find the most relevant journal

- We provide round the clock customer support

- Convenient online submission

- Thorough peer review

- Inclusion in PubMed and all major indexing services

- Maximum visibility for your research

Submit your manuscript at www.biomedcentral.com/submit
() Biomed Central 